Procedia of Engineering and Life Science Vol. 1 No.2 Juni 2021

Seminar Nasional \& Call Paper Fakultas Sains dan Teknologi (SENASAINS $2^{\text {st }}$ )

Universitas Muhammadiyah Sidoarjo

Doi link :

\title{
OPTIMIZATION OF CUTTING CHICKEN ROUTES
}

\section{OPTIMALISASI RUTE PENGAMBILAN AYAM POTONG}

\author{
Ovi Miru Sudandi ${ }^{1}$, Wiwik Sulistyowati ${ }^{2}$, \\ \{ovisudandi@gmail.com¹, wiwik@umsida.ac.id² \} \\ Program Studi Teknik Industri, Universitas Muhammadiyah Sidoarjo, Indonesia
}

\begin{abstract}
This study has the title Optimization of Chicken Cut Retrieval Route. The existence of this study aims to reduce the distance of chicken retrieval routes from cages to slaughter mills, as well as reduce the number of deaths and chicken kesetresan when descending from the chicken carrier fleet. The method in the study used saving matrix method and vehicle routing problem. The method of data collection used is to take primary data that is taken data from the location of cut parik and chicken coop taken by the fleet so far and secondary data taken dati preentase route from the slaughter plant to the chicken coop. And obtained the maximum chicken cut and decreased the death rate and chicken kesetresan with the length of saving matrix route $219.58 \mathrm{Km}$, using 5 trucks, spent fuel Rp. 141.263, and driver's salary of Rp. 26.250.000. While using vehicle routing problem route length $209.38 \mathrm{Km}$, using 5 trucks, spent fuel Rp. 134.775, and driver's salary of Rp. 26.250.000.
\end{abstract}

Keywords - Minimizing Chicken Retrieval Route With Saving Matrix Method and Vehicle Routing Problem (VRP)

Abstrak. Penelitian ini memiliki judul Optimalisasi Rute Pengambilan Ayam Potong. Adanya penelitian ini bertujuan untuk mengurangi jarak rute pengambilan ayam dari kandang menuju pabrik potong, serta mengurangi angka kematian dan kesetresan ayam saat turun dari armada pengangkut ayam. Metode pada penelitian menggunakan metode saving matrix dan vehicle routing problem. Metode pengumpulan data yang digunakan adalah mengambil data primer yaitu diambil data dari letak parik potong serta kandang ayam yang diambil armada selama ini dan data sekunder yang diambil dati preentase rute dari pabrik potong menuju ke kandang ayam. Dan didapatkan hasil potong ayam yang maksimal serta penurunan angka kematian dan kesetresan ayam dengan panjang rute saving matrix 219,58 Km, menggunakan 5 truck, menghabiskan bahan bakar Rp. 141.263, dan gaji sopir sebesar Rp. 26.250.000. Sedangkan menggunakan vehicle routing problem panjang rute 209,38 Km, menggunakan 5 truck, menghabiskan bahan bakar Rp. 134.775, dan gaji sopir sebesar Rp. 26.250.000.

Kata kunci : Meminimalisasi Rute Pengambilan Ayam Dengan Metode Saving Matrix dan Vehicle Routing Problem (VRP)

\section{Pendahuluan}

Masalah pangan merupakan kebutuhan pokok yang harus dipenuhi untuk masyarakat. Selain kebutuha pangan juga diperhatikan pula proses distribusi ayam yang baik, karena dengan adanya proses distribusi yang baik maka perputaran ayam di masyarakat bisa dipenuhi dengan baik. Maka diperlukannya cara untuk menanggulangi terjadinya kemacetan dalam kegiatan ditribusi tersebut. Misal mengoptimalisasi rute pengambilan ayam, penambahan jumblah armada pengangkut ayam, dan juga sopir yang profesional. Dengan cara seperti itu perusahaan akan terus berjalan lancar dan konsumen bisa terpenuhi secara baik dalam hal pangan.

Perusahaan ayam potong harus memiliki proses distribusi yang baik, karena kegiatan distribusi merupakan ujung tombak proses pemasaran sebagai penunjang peningkatan penghasilan perusahaan. Dengan seperti itu konsumen akan merasa puas dengan pelayanan perusahaan dalam hal distribusi ayam potong. Maka perusahaan harus memperbaiki proses distribusi yang buruk menjadi distribusi yang bagus, agar dalam kegiatan distribusi ayam potong bisa berjalan degan lancar dan perusahaan bisa meningkat dengan pesat.

Akan tetapi dari data lapangan selama ini ayam sampai di ppabr potong dalam keadaa stres dan ada yang mati, dikarenakan terlalu lama diatas armada dan juga berdesak desakan. Dari hal tersebut tidak sesuai dengan pernyataan [4] yang menyatakan formula yang mengacu pada suatu permasalahan 
Procedia of Engineering and Life Science Vol. 1 No.2 Juni 2021

Seminar Nasional \& Call Paper Fakultas Sains dan Teknologi (SENASAINS 2 ${ }^{\text {st }}$ )

Universitas Muhammadiyah Sidoarjo

Doi link :

mengenai penentuan sejumblah rute untuk sejumblah kendaraan yang berasal dari rumah potong ayam menuju ke sejumblah pelanggan yang tersebar secara luas. Vehicle routing problem memegang peranan penting pada manajemen distribusi dan telah menjadi salah satu permasalahan dalam optimasi kombinasi yang telah dipelajari secara luas. tujuan dari vehicle routing problem adalah meminimalkan jarak tempuh kendaran transportasi dalam melakukan pengiriman ke pelanggan - pelanggan sesuai dengan jumblah permintaannya masing - masing.

Pada penelitian optimalisasi rute metode yang digunakan antara lain saving matrix dan vehicle routing problem dikarenakan pebahasan yang dilakukan dalam laporan ini akan memperoleh hasil yang baik dan maksimal untuk merencanakan langkah kedepan setelah mengidentifikasi masalah distribusi ayam yang perlu ditingkatkan lagi.

\section{METODE}

Metode ini dipergunakan untuk menentukan rute, aktu, ongkos, dan jarak. Saving matrix digunakan dalam proses distribusi barang dari perusahaan kepada konsumen. Saving matrix bertujuan untuk proses pengiriman yang sanat efektif kepada konnsumen secara cepat. sehingga perusahaan tidak terlalu mengeluarkan biaya yang terlalu banyak utuk proses distribusi. Berikut proses perancangan distribusinnya yang meliputi, kapasitas armada harus terpenuhi untuk menuju ke suatu daerah yang dituju, memperhitungkan saving value merupakan cara penghematan jarak yang dapat dilakukan. Maka semakin besar nilai tersebut maka hasil yang diperoleh semakin hemat, Menentukan jarak pengiriman kepada konsumen dengan menggunan aplikasi google maps.

Vehicle routing problem adalah sebuah istilah atau nama formula yang mengacu pada suatu permasalahan mengenai penentuan sejumblah rute untuk sejumblah kendaraan yang berasal Rumah Potong Ayam menuju ke sejumblah pelanggan yang tersebar secara luas. VRP memegang peranan penting pada manajemen distribusi dan telah menjadi salah satu permasalahan dalam optimasi kombinasi yang telah dipelajari secara luas. tujuan dari VRP adalah meminimalkan jarak tempuh kendaran transportasi dalam melakukan pengiriman ke pelanggan - pelanggan sesuai dengan jumblah permintaannya masing - masing[4].

Vehicle routing problem adalah metode yang digunakan banyak perusahaan untuk mengatasi masalah dalam perencanaan dan pengambilan keputusan. Yaitu guna untuk proses distribusi dan menentukan rute yang optimal, yaitu dari perusahaan kepada para konsumen. Metode ini biasa digunakan untuk mengatasi jalur atau rute - rute yang menjadikan masalah dalam kegiatan distribusi barang perusahaan [5]. Tujuannya yaitu untuk meminimumkan dalam kegiatan berdistribusi. VRP yang sederhana dapat digambarkan seperti berikut, truck / pickup berjalan dari gudang menuju ke konsumen konsumen dan kembali ke gudang kembali, satu pelanggan dilayani oleh 1 kendaraan dari gudang, truck / Pickup hanya membawa barang sesuai kapasitas kendaraan, tidak lebih atau tidak kurang, dan perusahaan harus dapat menentukan jalur distribusi barang dari gudang menuju pelanggan atau konsumen dalam jarak seminimum mungkin agar biaya operasional juga minimum.

diagram alir penelitian untuk mengetahui proses distribusi ayam dari kandang menuju ke pabrik potong. Gambaran umum dari keseluruhan sistem yang dirancang dapat terlihat pada alur penelitian yang ditunjukkan oleh Gambar 1. 
Procedia of Engineering and Life Science Vol. 1 No.2 Juni 2021

Seminar Nasional \& Call Paper Fakultas Sains dan Teknologi (SENASAINS $2^{\text {st }}$ )

Universitas Muhammadiyah Sidoarjo

Doi link :

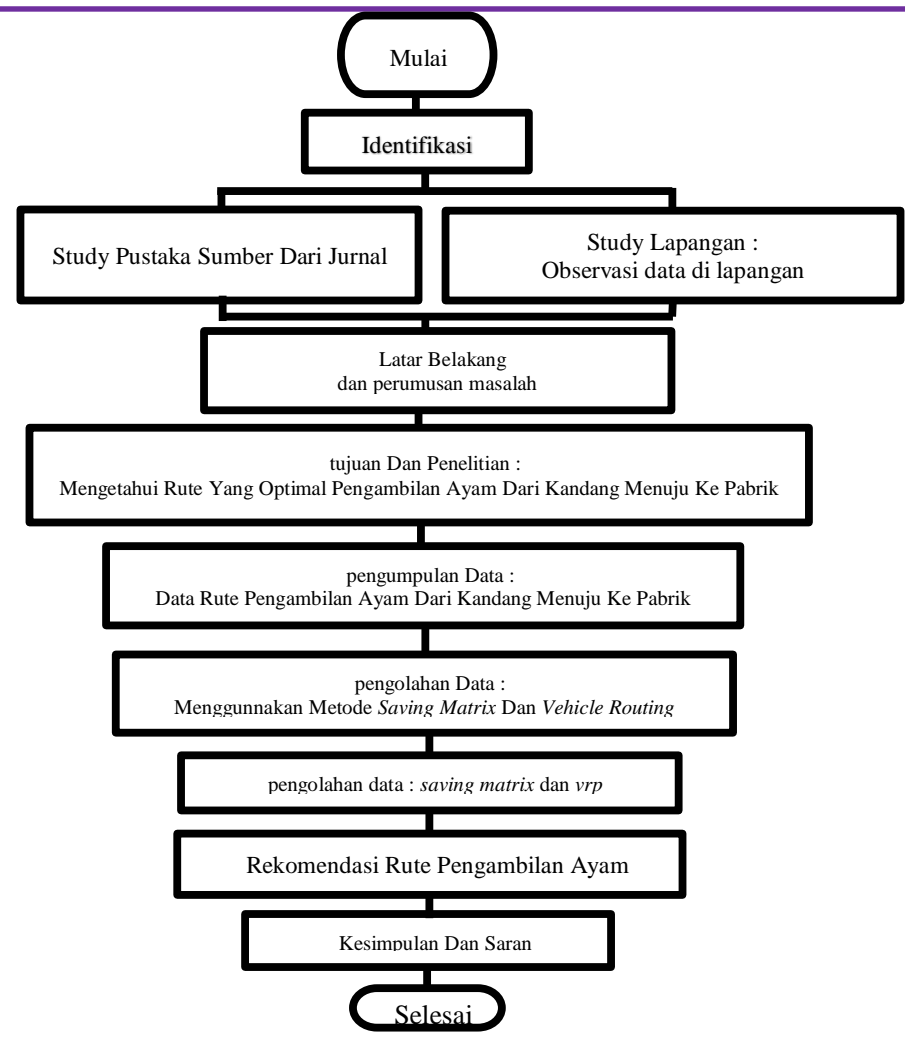

Gambar 1. Alur Penelitian

Berdasarkan alur penelitian pada gambar 1 telah dijelaskan bahwa tahapan-tahapan dimulai dari pengumpulan data dan informasi, tahapan kedua pengolahan data, tahapan ke tiga analisa dan pembahasa, dan tahapan ke empat rekomendasi.

III. Hasil dan Pembahasan

Tabel 1. Jarak Pabrik Ke Tiap Kandang

\begin{tabular}{|c|c|c|c|c|c|c|}
\hline \multirow[b]{2}{*}{ No } & \multirow[b]{2}{*}{ Alamat Kandang } & \multirow[b]{2}{*}{ Kandang } & \multirow[b]{2}{*}{$\begin{array}{c}\text { Jumlah } \\
\text { Ayam }\end{array}$} & \multicolumn{3}{|c|}{ Present } \\
\hline & & & & $\begin{array}{c}\text { Jarak/ } \\
\text { km }\end{array}$ & $\begin{array}{c}\text { ase } \\
\text { Jalan }\end{array}$ & $\begin{array}{l}\text { Bahan } \\
\text { Bakar }\end{array}$ \\
\hline 1. & Rejoso Pasuruan & 1 & 1350 & 29,49 & $75 \%$ & $3,6 \mathrm{~L}$ \\
\hline \multirow[t]{2}{*}{2.} & probolinngo & 2 & 400 & 29,71 & $75 \%$ & $3,7 \mathrm{~L}$ \\
\hline & Wonoayu Leces & 3 & & 20,16 & $65 \%$ & $2,5 \mathrm{~L}$ \\
\hline \multirow[t]{2}{*}{3.} & Lumajang & & 700 & & & \\
\hline & Wonorejo & 4 & & 22,62 & $65 \%$ & $2,8 \mathrm{~L}$ \\
\hline 4. & Lumajang & & 450 & & & \\
\hline \multirow[t]{2}{*}{5.} & Juanda Lumajang & 5 & 350 & 7,81 & $60 \%$ & $1 \mathrm{~L}$ \\
\hline & Total & & 3.250 & 109,79 & & $13,6 \mathrm{~L}$ \\
\hline
\end{tabular}

\section{A. Jarak pabrik potong dengan tiap kandang}

Berdasarkan tabel di atas dapat diketahui alamat kandang ayam yang dituju oleh armada pabrik. Yang beralamat kandang no 1 Rejoso Pasuruan dengan jumblah muatan 1.350 ekor, dengan jarak dari pabrik potong 29,49 Km, presentase jalan sebesar 75\%, dan membutuhkan bahan bakar sebesar 3,6 liter. Kandang no 2 Probolinggo dengan jumblah muatan 400 ekor, dengan jarak dari kandang 1 sebesar 29,71 $\mathrm{Km}$, presentase jalan sebesar 75\%, dan membutuhkan bahan bakar sebesar 3,7 liter. Kandang no 3 Wonoayu Lumajang dengan jumblah muatan 700 ekor, dengan jarak dari kandang 2 sebesar 20,16 Km, presentase jalan sebesar 65\%, dan membutuhkan bahan bakar sebesar 2,5 liter. 
Procedia of Engineering and Life Science Vol. 1 No.2 Juni 2021

Seminar Nasional \& Call Paper Fakultas Sains dan Teknologi (SENASAINS 2st)

Universitas Muhammadiyah Sidoarjo

Doi link :

Kandang no 4 Wonorejo Lumajang dengan jumblah muatan 450 ekor, dengan jarak dari kandang 3 sebesar 22,62 Km, presentase jalan sebesar 65\%, dan membutuhkan bahan bakar sebesar 2,8 liter. Kandang no 5 Probolinggo dengan jumblah muatan 350 ekor, dengan jarak dari kandang 4 sebesar 7,81 $\mathrm{Km}$, presentase jalan sebesar 60\%, dan membutuhkan bahan bakar sebesar 1 liter.

\section{B. Penerapan saving matrix dan vehicle routing problem dalam meminimalisasi rute}

Berikut perbandingan dalam menggunakan metode saving matrix yaitu dimana sebelum menggunakan metode dan sesudah menggunaka metode.

\section{1) Sebelum Menggunakan Metode}

Pada analisa ini perhitungan awal sebelum menggunakan metode saving matrix dan vehicle routing problem.

Tabel 2. Sebelum Menggunakan Metode

\begin{tabular}{|c|c|c|c|c|}
\hline No & Rute Awal & Gaji Sopir dan Kernet & $\begin{array}{l}\text { Bahan Bakar } \\
\text { (Rp) }\end{array}$ & Hasil Potongan ( ayam fresh ) \\
\hline & \multirow[t]{2}{*}{$219,58 \mathrm{Km}$} & $\begin{array}{l}\text { Sopir }=3 \mathrm{Jt} \\
\text { Kernet }=2,2 \mathrm{Jt}\end{array}$ & 141.354 & $\begin{array}{l}\text { Kurang baik, karena sampai di pabrik ayam } \\
\text { banyak yang kurang sehat dan bahkan sampai } \\
\text { mati, disebabkan terlalu lama dijalan terkena }\end{array}$ \\
\hline & & $\begin{array}{l}\text { Maka total } \\
\text { kesluruhan sebesar = } \\
5,2 \mathrm{Jt}\end{array}$ & & $\begin{array}{l}\text { paparan sinar matahari dan panasnya mesin } \\
\text { armada. }\end{array}$ \\
\hline
\end{tabular}

Pada tabel diatas rute sebelum menggunakan metode saving matrix dan vehicle routing problem panjang rute sebesar 219,58 Km. Dengan gaji sopir sebesar Rp. 5.250.000, Rp. 3.000.000 gaji sopir selama 1 bulan dan Rp. 2.250.000 gaji kernet selama 1 bulan. Kebutuhan bahan bakar Rp. 141.354 yang digunakan 1 armada pulang pergi. Sedanga untuk hasil potong sendiri hasil yang diperoleh perusahaan kurang baik, ayam terlalu lama di jalan dan berdesak desakan karena hanya menggunakan 1 armada.

\section{2) Setelah Menggunakan Metode Saving Matrix}

Pada analisa berikut sudah meggunakan metode saving matrix yaitu dimana rute, gaji sopir, bahan bakar, dan hasil potong sudah berbeda.

Tabel 3. Setelah Menggunakan Metode Saving Matrix

\begin{tabular}{|c|c|c|c|c|}
\hline No & $\begin{array}{l}\text { Rute saving } \\
\text { matrix }\end{array}$ & $\begin{array}{l}\text { Gaji sopir dan } \\
\text { Kernet }\end{array}$ & $\begin{array}{l}\text { Bahan Bakar } \\
\text { (Rp) }\end{array}$ & Hasil Potongan \\
\hline 1. & $219,58 \mathrm{Km}$ & $5,2 \mathrm{Jt} \times 5=26 \mathrm{Jt}$ & 141.263 & $\begin{array}{l}\text { Hasil potongan ayam sangat bagus, } \\
\text { karena ayam sebelum dipotong dalam } \\
\text { keadaan sehat. }\end{array}$ \\
\hline
\end{tabular}

Berdasarkan hasil analisa diatas yang sidah menggunakan metode saving matrix dimana jalur tetap sebesar Rp. 219,58 Km, gaji sopir menjadi Rp. 26.250.000 karena menggunakan 5 armada dengan jumblah 5 sopir dan 5 kernet, dan hasil potong yang sangat bagus. Dimana ayam lebih cepat untuk sampai di pabrik potong dalam keadaan sehat.

\section{3) Setelah Menggunakan Metode Vehicle Routing Problem}

Pada analisa tabel 5 sudah menggunakan metode vehicle routing problem dimana panjang rute berbeda, gaji sopir dan kernet berubah, dan hasil potong ayam menjadi bagus. 
Procedia of Engineering and Life Science Vol. 1 No.2 Juni 2021

Seminar Nasional \& Call Paper Fakultas Sains dan Teknologi (SENASAINS $2^{\text {st }}$ )

Universitas Muhammadiyah Sidoarjo

Doi link :

Tabel 4. Setelah Menggunakan Metode Vehicle Routing Problem

\begin{tabular}{lllll}
\hline No & $\begin{array}{l}\text { Rute Vehicle } \\
\text { Routing } \\
\text { Problem }\end{array}$ & $\begin{array}{l}\text { Gaji Sopir } \\
\text { dan Kernet }\end{array}$ & $\begin{array}{l}\text { Bahan Bakar } \\
(\mathrm{Rp})\end{array}$ & $\begin{array}{l}\text { Hasil Potonangan } \\
\end{array}$ \\
\hline 1. & $209,38 \mathrm{Km}$ & $\begin{array}{l}5 \text { armada x 5,2 } \\
\mathrm{Jt}=26 \mathrm{Jt}\end{array}$ & 134.775 & $\begin{array}{l}\text { Hasil potongan sangat maksimal, } \\
\text { karena sebelum dipotong ayam } \\
\text { dalam keadaan tidak stres. }\end{array}$ \\
& & & $\begin{array}{l}\text { Sehingga daging yang didapat } \\
\text { dalam keadaan segar. }\end{array}$ \\
& & &
\end{tabular}

Berdasarkan hasil analisa diatas rute yang awalnya 219,58 Km menjadi 209,38 Km karena sudah menggunakan metode vehicle routing problem, dengan gaji sopir Rp. 26.250.000 yang menggunakan 5 sopir dan 5 kernet dalam 5 armada yang digunakan, jumblah bahan yang dibutuhkan sebesar Rp. 134.775, dan hasil potonng yang sangat baik karena ayam tidak ada yang stress maupun mati karena lebih cepat untuk sampai di pabrik potong.

\section{KESIMPULAN}

Berdasarkan metode saving matrix dan vehicle routing problem dapat diambil kesimpulan sebagai berikut, perusahaan harus menggunakan 5 armada, karena jika mengggunakan 1 armada ayam terlalu lama dijalan, harus mencari sopir yang profesional, total gaji yang dikeluarkan perusahaan untuk sopir menggunakan metode saving matrix sebesar Rp. 26.250.000, panjang rute menggunakan metode saving matrix sebesar 219,58 Km, kebutuhan bahan bakar yang digunakan dalam mettode saving matrix sebesar Rp. 141.315, total gaji sopir yang dikeluarkan untuk metode vehicle routing problem sebesar Rp. 26.250.000, panjang rute menggunakan metode vehicle routing problem sebesar $209,38 \mathrm{Km}$, dan kebutuhan bahan bakar yang digunakan sebesar Rp. 134.775.

\section{REFERENSI}

[1] Herlina. 2015. "Pengaruh Jenis Dan Waktu Pemberian Ransum Terhadap Performans Pertumbuhan Dan Produksi Ayam Broiler”. Fakultas Pertanian. Universitas Musi Rawas. Vol 10. No. 2.

[2] Indrawati. 2016. "Penentua Rute Otimal Pada Pengakutan Sampah Di Kota Palembang Dengan Menggunakan Metode Saving Matrix.” Jurusan Matematika. Universitas Sriwijaya. Vol 18. No. 3.

[3] Jumiati. 2017. “Bobot Potong, Karkas, Giblet Dan Lemak Abdominal Ayam Broiler Yang Temulawak ( Curcumaxanthorrhiza, Roxb ).” Jurusan Peternakan. Fakultas Peternakan. Vol 4. No 3.

[4] Kusumawardani. 2017. Penentuan Rute Distribusi Daging Ayam Menggunakan Metode Clarke And Wright Savings Dan Algoritma Genetika." Jurusan Pendidikan Matematika. FMIPA UNY. Vol 6. No 4.

[5] Lalang. 2018. "Vehicle Routing Problem Time Windows Dengan Pengemudi Sesekali." Journal of Mathematics and Its Applications. Hal 87-98.

[6] Ngantung. 2019. “Analisis Rentabilitas Usaha Peternakan Ayam Ras Petelur Ud. Tetey Permai Di Kecamatan Dimembe Kabupaten Minahasa Utara." Fakultas Peternakan. Universitas Sam Ratulangi. Vol 39. No 1.

[7] Suparjo. 2017. "Metode Saving Matrix Sebagai Metode Alternatif Untuk Efisiensi Biaya Distribusi." Fakultas Ekonoi dan Bisnis. UNTAG Semarang. Vol 32. No 2.

[8] Wardhana. 2019. "Penentuan Rute Armada Pengiriman Pt.Aaa Menggunakan Algoritma Two-Phase Tabu Search Pada Vehicle Routing Problem With Heterogeneous Fleet And Time Windows Untuk Mengatasi Keterlambatan Pengiriman." Fakultas Rekayasa Industri. Vol 6. No 2. 